\title{
Sinhazinhas entre gentis e hostis (Nacionais e estrangeiros no teatro brasileiro do século XIX)
}

Carlos Eduardo Schmidt Capela I UFSC

\begin{abstract}
Resumo: No teatro brasileiro do século XIX há uma série de peças que se caracterizam pela presença, entre os protagonistas, de personagens de estrangeiros. O ensaio analisa modos como tais personagens atuam no enredo das peças, sendo de maneira geral vistas ou como indesejáveis, figurando como agentes desestabilizadores, ou como seres desejados pelas personagens nacionais com quem convivem, dado o aporte de civilização que trariam. Nas peças, com isso, delineiam-se imagens ideais sobre o perfil futuro projetado para a nação brasileira.

Palavras-chave: Teatro brasileiro do século XIX; representações de estrangeiros; literatura e nacionalismo.
\end{abstract}

Boa parte da prosa de ficção brasileira do século XIX é feita a partir de enredos que giram em torno de conflitos amorosos. Sendo assim, sobre os desenlaces destas ficções é possível dizer, grosso modo, que eles se encaminham para direções opostas: ou desandam em tragédias, decorrentes da impossibilidade da união dos amantes, ou, após a resolução de contratempos, culminam com, ou prenunciam, os acordes do "hino misterioso do santo amor conjugal", para lembrar a forma lapidar com que José de Alencar encerra o clássico Senhora. 
Na medida em que desenlaces nada mais são que o resultado de desdobramentos de séries de eventos, é possível perceber que esta dicotomia embute um fundo, ou base comum. Sejam trágicos, como em Inocência, do Visconde de Taunay, ou felizes, caso do citado Senhora, eles são fruto do caráter mais ou menos irredutível, menos ou mais contornável, dos impedimentos que se interpõem à consagração do amor, que figura sempre como propósito almejado. Interdições funcionam, portanto, ao modo de molas propulsoras, como motivação, revelando-se fundamentais para a coordenação das pulsões maiores que alimentam o enredo de diversas das ficções do período.

Como este ensaio tem por motivo uma série de peças de teatro, quase todas encenadas ou publicadas na segunda metade do 1800, é assim natural, visto tais textos constituírem um subgrupo daquele conjunto maior, que interdições ou impedimentos sejam tomados como ponto de partida para as reflexões aqui apresentadas.

De maneira usual resolvidas e afastadas, nas peças em questão as interdições são quase sempre causadas por fatores ou elementos externos aos casais que ocupam o centro do núcleo dramático. Podem resultar da intervenção de uma terceira personagem, que cria empecilhos, dificultando e adiando a união dos amantes, ou da influência do ambiente social, que reclama ou impõe sistemas de valores ou normas de comportamento que, contaminando um dos membros do casal, faz que este se afaste do parceiro. Ocorre, nesse último caso, uma espécie de impedimento cujo fundamento é de ordem ideológica, o uso do masculino para qualificar aquele que é desprezado constituindo mais que complacência com respeito a normas - sintomaticamente, apenas mulheres são desviadas do trajeto do amor puro e sincero, por normas ou indivíduos, ainda que por vezes somente durante breve intervalo, fato que, ademais, joga mais lenha no fogo simbólico que alimenta a atribuição e concomitante avaliação de diferenças.

As peças aqui tratadas têm em comum o fato de contarem, entre seus protagonistas, seja com personagens de estrangeiros, ${ }^{1}$ que introduzem e

1. Estrangeiro é aqui tomado não como um mero qualificativo, mas como um conceito. Por oposição a imigrante e colono, o estrangeiro é um indivíduo em quem os efeitos da condição social, que além de capital financeiro compreende educação e qualificação profissional, sobrepõem-se aos efeitos da origem nacional. Proveniente de nações dominantes, "mesmo se residir em um país estrangeiro durante toda a sua vida, ser[á] tratado com o respeito devido a sua qualidade de estrangeiro". (Conforme SAYAD, 1998, p. 244). Para uma melhor explanação do conceito de estrangeiro, em contraste com os conceitos de imigrante e colono, ver CAPELA, 2003. 
representam valores considerados estranhos à sociedade brasileira, seja com personagens de nacionais que cumprem o mesmo papel. Invariavelmente masculinas, estas personagens de estrangeiros ou de brasileiros estrangeirados irão participar de modo direto das tramas que condicionam os sucessos amorosos. Postulada a diferença nacional como fulcro das ações dramáticas, descortinamse duas possibilidades básicas: a união abençoada pode ser entre um estrangeiro, ou um brasileiro estrangeirado, e a mocinha nacional, sendo no caso a interdição resultante da interferência de algum indivíduo pertencente ao espaço brasileiro, ou, inversamente, é um estrangeiro, ou um brasileiro estrangeirado, que se interpõe entre os amantes brasileiros. Nas peças, a predominância absoluta, entre ambas, é desta última, a atuação de estrangeiros ou estrangeirados sendo descrita de modo a realçar o sentido desestabilizador a ela atribuído, seu caráter de impropriedade.

É o que se constata em comédias como O tipo brasileiro (1872), de França Júnior, ou Os dous ou o inglês maquinista (1842), de Martins Pena, nas quais personagens efetivamente estrangeiras são introduzidas em cena. O inglês Gainer, de Os dous ou o inglês maquinista, logo de saída se revela um refinado finório, buscando conseguir do governo imperial privilégios para a realização de empreendimentos mirabolantes: produzir açúcar a partir de ossos e construir uma máquina de beneficiar bovinos. Procura ainda, ao mesmo tempo, obter da família que o recepciona a mão de Mariquinha, a brasileira virtuosa, ocultando suas verdadeiras intenções a respeito da jovem. É Felício, o rapaz brasileiro bom caráter e de fato sinceramente apaixonado pela moça, que percebe seu intento de, desposando-a, apossar-se do dote da família.

Os propósitos nada nobres do estrangeiro, e sua pouca consideração pelos brasileiros, são também expressos de modo direto, por ele próprio. Como quando confessa, no seu português estropiado que acaba por acentuar seu alheamento em relação ao universo brasileiro - e que o torna ridículo aos olhos dos espectadores e leitores -, que "Destes tolas eu quero muito".

2. PENA, s/d, p. 70. Confissões como essas surgem em monólogos à parte, com o que é insuflado nos espectadores um sentimento de animosidade contra a própria personagem que as profere. A estratégia é recorrente nas peças do período que trazem representações de estrangeiros, cujas falas são comumente escritas num português deformado, índice da origem não brasileira. Sistematizado, o processo dará origem à linguagem macarrônica que irá notabilizar personagens de estrangeiros e imigrantes de Alexandre Marcondes Machado (com Juó Bananére), Horácio Campos (com Furnandes Albaralhão) e Aparício Torelly, com suas diversas interpretações de alemães, portugueses, italianos e "turcos". 
O texto opera com base em uma partição simples, maniqueísta: de um lado estão os interesseiros, figurando aqui, junto a Gainer, Negreiros, um traficante de escravos também de olho no dote da menina. Do outro encontra-se Felício, cuja atuação vai no sentido de evitar o êxito dos primeiros. Conseguindo, ao final, o intento perseguido, sua intervenção lhe garante a mão de Mariquinha, que funciona como uma espécie de recompensa a sua fidelidade aos valores puros e castos, embora ingênuos, que organizaria a boa sociedade brasileira. Do ponto de vista do público, cuja cumplicidade é alimentada ao longo de toda a peça, fica desta forma preservado o resguardo das virtudes nacionais, encarnadas pelo jovem herói.

O tipo brasileiro apresenta não só um didatismo de ordem semelhante como um esquema de ação análogo. Aqui a sinhazinha chama-se Henriqueta, e sua complementaridade com o jovem brasileiro é, sem maiores sutilezas, indicada já pelo nome a este conferido: Henrique. Ambos efetivamente se amam, e o principal impedimento à sua união é a presença de um estrangeiro, outra vez um inglês - Mr. John Read. Como seu conterrâneo Gainer, este ambiciona conseguir, com o casamento, o dinheiro do dote, e possui também um projeto estapafúrdio, "encanar cajuada em toda a cidade" (do Rio de Janeiro), para o que procura obter privilégios do governo. Conta ainda com a simpatia do pai da moça, cuja desmedida admiração por tudo que seja estrangeiro é completada por uma aversão ao que quer que seja nacional, pessoas inclusive. Daí seu desprezo por Henrique e a alta consideração por Mr. Read, a quem trata como "distinto hóspede", "bretão às direitas", "dono de um cérebro maravilhosamente organizado", etc. Daí, também, sua decisão de obrigar a filha a aceitar o inglês em casamento.

França Júnior, através da personagem de Henrique, ataca a tendência ao estrangeirismo que identificava na sociedade carioca. Assim, num dos atos da peça, em diálogo com Teodoro, o pai de sua amada, o jovem brasileiro realiza um discurso de alto teor nacionalista, e moralista, com o que critica tal postura:

O Senhor Teodoro é o tipo do brasileiro. Não há país nenhum do mundo que não tenha orgulho de suas glórias, de suas instituições e de suas coisas. (...) A nossa indústria definha, humilhada por nós mesmos. (...) Vamos de dia em dia perdendo o tipo na família, nos hábitos, nos 
costumes, e finalmente até já começamos a prostituir a própria língua que falamos.

John Read, por sua vez, constitui paradigma do estrangeiro disposto a desfrutar tudo que o Brasil possa oferecer, e a explorar as riquezas que aqui divisa. Isso fica patente em várias passagens, por exemplo quando, com sua linguagem capenga, explicita o que achara do Norte do país, de onde voltara:

Beatiful! Mas não tem passa lá muite bem. Falta confortável de vida, que este terra não conhece. Mim quando vai p'ra Ingliterre, escreve uma livra, e há de mostra o que estar Brasil. Estar gosta um pouco de Pernambiúco, muite de Pará. Oh! Pará is very fine. Eu compre lá muite borracha, e leva uma carregamenta para Liverpool. Não estar muite querida d'Amazonas... (p. 145)

O estratagema empregado por Henrique para afastar o rival sinaliza a justeza de seu diagnóstico. Opta por empregar armas idênticas às do inimigo e, após se disfarçar, apresenta-se como um estrangeiro, um francês interessado em obter a proteção de Teodoro, "parce qu'on ma dit que monsieur protege todos os estrangeiros que vêm ô Brésil” (p. 146). Anuncia o indefectível projeto estapafúrdio, "montar aqui um grande fabrique de pomade" (p. 147), e vai se contrapondo ao inglês. Seu jogo de cena culmina num cortejo quase descarado a Henriqueta (que nesse momento, aliás, nada sabe da encenação), o que causa no inglês uma crise de ciúmes que desanda numa cômica tentativa de agressão. Quando anuncia o nome francês que para si inventara, o rival lhe pergunta se morava em Paris, num endereço preciso. Percebendo ali o indício de algo suspeito, Henrique confirma o endereço, o que traz visível incômodo ao oponente.

3. FRANÇA JÚNIOR, 1980, p. 140-141 (as indicações das páginas serão doravante expressas no corpo do texto, após as citações). O tema do desprezo pela língua portuguesa é não só mencionado mas também ilustrado. Em diálogo com a filha, Teodoro desmerece o português, ao compará-lo com outros idiomas europeus: “(...) esta maldita língua portuguesa é tão cheia de ãos, ãos, ãos, que nos assemelham, quando conversamos, a uma matilha de cães a ladrar. (...) não há língua nenhuma no mundo tão burlesca e tão pouco significativa como a nossa". (p. 143). Também em Os dous ou o inglês maquinista surgem críticas ao estrangeirismo, por exemplo quando uma personagem, com nítido orgulho, comenta sobre o domínio do francês por sua filha: "Fala francês e daqui a dous dias não sabe mais falar português" (PENA, s/d, p. 73). 
$\mathrm{Na}$ seqüência este acaba confessando uma dívida considerável com uma casa comercial parisiense, cujo nome era, por feliz acaso, o mesmo daquele escolhido por Henrique. O rapaz consegue assim desmascarar o inglês, que sem saber que Teodoro a tudo escutava confessa inclusive ser o dote o motivo maior de seu interesse por Henriqueta. Na conclusão, Teodoro, após enxotar Mr. Read, nega a mão da filha ao francês, prometendo-a a Henrique, que afinal se revela e lança ao futuro sogro uma última moralização nacionalista: “(...) um brasileiro, ainda quando nenhum préstimo tenha, serve ao menos para desmascarar um tratante. Receba calado esta lição, e aprenda a respeitar a terra das bananas e palmeiras, onde canta o sabiá" (p. 155). ${ }^{4}$

Outro Mr. James, também inglês e também velhaco, interessado unicamente em auferir, no Brasil, o máximo de riqueza em um mínimo de tempo, é uma das personagens centrais de Caiu o ministério! (1882), também de França Júnior. Embora a definição da personagem do estrangeiro seja em larga medida mantida, permanecendo próxima de um padrão que beira o estereótipo mais cru, França Júnior, nesta peça, propõe um leque mais amplo de tipos humanos e de situações narrativas, que incorporam inclusive alusões ao funcionamento do Estado na época do Segundo Reinado. Mr. James possui seu projeto mirabolante, construir uma linha férrea até o Corcovado, com o detalhe absurdo de que pretendia utilizar cachorros como força motriz. É em função da realização de seus planos empresariais que ele vai se aproximar da heroína, Beatriz, cujo pai fora nomeado presidente do conselho de ministros do Governo Imperial.

O perfil de Beatriz é revelador da perspectiva ácida que França Júnior reserva aos protagonistas centrais da comédia, independentemente de suas origens. O caráter da moça oscila entre os pólos da futilidade e da vaidade, de que decorre um forte sentimento de orgulho pessoal e um desprezo ferino por concorrentes ou pretendentes que julga pouco dignos de com ela privarem. Assim como ela, os demais brasileiros que comparecem à peça assumem ares de alta soberba, o que não basta, contudo, para ocultar o alcance mesquinho de seus planos e ações. O Dr. Raul Monteiro, por exemplo, ao saber que o pai de Beatriz tornara-se presidente do conselho, deixa de considerá-la péssimo

4. Em Quase ministro (1862), de Machado de Assis, há a personagem de um alemão, Müller, que faz o papel do estrangeiro espertalhão que tenta ludibriar os brasileiros. A peça contudo não explora situações amorosas. 
partido ("Nessa não caio eu! É pobre como Jó, e mulher sem isto (Sinal de dinheiro) está se ninando." $)$ e, empenhado antes de tudo em conseguir um emprego, passa a cortejá-la com ardor hipócrita.

Há portanto, no caso, menos oposição que identidade entre nacionais e não nacionais, já que em relação à moça atitude idêntica será tomada pelo inglês, que tem inclusive opiniões semelhantes às de Raul sobre Beatriz:

MR. JAMES - Semana passada, mim estar no baile de Cassino, diz àquela menina, que ele estar bonita; menina estar estúpida, e diz a mim - How? Por que voucê não mi pede a papai? PEREIRA - Bravo! E por que não se casa com ela? MR. JAMES - Ob! no; mim não estar vem a Brasil pra casa. Mim vem aqui pra faz negócia. Menina não tem dinheiro, casamento estar mau negócia. No, no, no quer (...) (p. 181; itálicos do original).

A presença do estrangeiro serve ainda a França Júnior para introduzir uma avaliação externa, e britânica, com todo o peso simbólico que daí advém, sobre a sociedade brasileira, com o que enfatiza alguns vícios tidos então como comuns no domínio da esfera pública. A instabilidade política, por exemplo, é tema de um diálogo entre Mr. James e Raul:

MR. JAMES - (...) Brasileira não pode suporta governo muite tempa. Quando ministra começa a faz alguma cousa, tudo grita - No presta, homem estar estúpida, homem estar tratanta...

RAUL - Infelizmente é a pura verdade.

MR. JAMES - Quando outra sobe diz mesma cousa, muda presidenta de provincia, subdelegada, inspetor de quarteirão, e país, em vez de anda, estar sempre parada. (p. 185; itálicos do original).

A auto-complacência dos brasileiros com relação a si mesmos, de par com a efusiva avaliação da ação de estrangeiros, é destacada em diálogo entre de D. Filomena, esposa do Conselheiro Brito e mãe de Beatriz, a própria Beatriz e Mr. James. O diagnóstico dela tem por complemento comentários do inglês sobre a passividade dos brasileiros, que segundo ele se materializaria, entre outras coisas, pela passividade e pelo pendor à retórica.

5. FRANÇA JÚNIOR, 1980 (Tomo II), p. 181 (itálicos do original). 
BEATRIZ - O seu projeto é a great attraction do dia. MR. JAMES - Projeto estar muita grandiosa (...).Carros sai daqui de Cosme Velha, e sobe Corcovado em vinte minutas.

BEATRIZ - E estes cachorros que estão aqui pintados?

MR. JAMES - Senhorras não entende deste cousa: mim fala com pai de vosmecê, explica o que é todos esses cachorras.

FILOMENA - Tudo quanto temos de bom devemos aos senhores estrangeiros.

BEATRIZ - C'est vrai. Os brasileiros, com raras exceções, não se ocupam destas coisas.

MR. JAMES - Brasileira estar muito inteligenta; mas estar também muito preguiça. Passa vida na rua do Ouvidor a fala de política, pensa só de política de manhã até a noite. Brasileira quer estar deputada, juiz de paz, vereador...

(...)

MR. JAMES - How! Toda ministéria estar doutor em direita?

BEATRIZ - Sim, senhor.

MR. JAMES - Na escola de doutor em direita estuda marinha, aprende planta batatas e café, e sabe todas essas cousas de guerra?

FILOMENA - Não, senhor.

BEATRIZ - Estudam-se leis.

MR. JAMES - No Brasil estar tudo doutor em direita. País no indireita assim... (p. 194-195; itálicos do original).

Mesmo o Conselheiro Brito, que demonstra alguns escrúpulos quanto ao trato com a coisa pública, acaba por se deixar envolver por esposa e filha, que pedem sua interferência direta para conseguir o privilégio solicitado pelo inglês e, de quebra, emprego para o Dr. Raul. O empenho do Conselheiro em defesa do projeto apresentado por Mr. James acaba por custar-lhe a chefia do governo. Com isso, os pretendentes à mão de Beatriz se retiram. A moça, porém, é brindada com a presença de Felipe, jovem que nutria sincera paixão por ela, e que até então recebera da moça desprezo em razão de sua pobreza, até mesmo de espírito. Em favor de Felipe conta a sorte de ter tirado um alto prêmio da loteria, o que constitui razão suficiente para que a jovem aceite o pedido de casamento. A peça, nesse sentido, lança um olhar fortemente irônico sobre a sociedade urbana brasileira, sem incorrer, pelo menos no nível do argumento da peça propriamente dito, em oposições binárias simples, já que tanto brasileiros quanto estrangeiros são igualados pela mediocridade e pela busca da satisfação de interesses imediatos. 
A exploração de situações dramáticas que põem em questão o apego desmedido de brasileiros por seres e coisas estrangeiras está presente em outras peças do período. É o caso de A torre em concurso (1863), comédia burlesca de Joaquim Manuel de Macedo que, embora não traga personagens de não nacionais, tem como referência básica projeções a eles atribuídas. A ação se passa no interior do país, na província. A trama gira em torno de um concurso, promovido pelas autoridades de uma pequena cidade, para a seleção de um projeto visando a construção da torre da igreja, em cujo edital surge a esdrúxula exigência de que todo concorrente teria que não apenas ser, forçosamente, engenheiro, mas ainda "inglês de nação e ter vindo para o Brasil já barbado".

Claro que a exigência é contestada por um engenheiro nacional, o jovem Henrique, e será aproveitada por dois charlatões, ambos brasileiros e atores mambembes, que se fazem passar por ingleses, e engenheiros. A trama traz ainda, como usual, uma moçoila solteira e encantadora, Faustina, que vive uma paixão por Henrique, recíproca. O impedimento, nesse caso, tem os supostos estrangeiros não como agentes, mas como instrumentos. Isso porque a tia de Faustina, uma velhota também interessada em Henrique, procurando afastar a concorrente consegue que o pai da moça, seu irmão, prometa a mão da sobrinha, e o dote a que faz juz, ao "inglês" ganhador do concurso.

Os nós se desatam na conclusão, quando os farsantes são desmascarados e Henrique, nomeado engenheiro da Província, torna-se o responsável pela edificação da torre, com o que conquista o direito de desposar Faustina, e levar o dote, dado que, claro, é deixado de lado pelo dramaturgo. Antes porém surge, da boca de um dos falsos estrangeiros, um julgamento nada abonador quanto a alguns aspectos da sociedade brasileira, tomados como argumentos para justificar toda a farsa:

(...) não há professores de colégios que ensinam o que nunca souberam?... não se transforma em diplomata um boneco que sabe somente namorar e fazer cortesias?... não se improvisam estadistas da noite para o dia?... não se faz de um homem de juízo torto um juiz de direito?... o patronato não é um santo milagroso que torna um jacaré em Adônis, um tratante em benemérito da pátria, e uma tábua rasa em sábio da Grécia?... pois então

6. MACEDO, 1979, p. 175 (as indicações das páginas serão doravante apresentadas no corpo do texto, após as citações). 
por que também não poderei ser um engenheiro de torre, e, ainda melhor, casar com a filha do capitão João Fernandes?... (p. 221).

Delineia-se assim, e sobretudo porque em torno dos falsos ingleses se organizam dois partidos que se engalfinham na eleição que deveria escolher um dentre eles, uma crítica bem humorada ao jogo político tal como então praticado no Brasil, cujo ponto de partida, importa frisar, é uma sátira ao estrangeirismo dominante, traduzido em versão cabocla.

Surgem ainda, em peças do período, personagens de estrangeiros que nos textos ocupam posições secundárias, em correspondência, aliás, com a menor importância de seu lugar social: são os criados e os preceptores a serviço da alta burguesia brasileira. Em Luxo e vaidade (1860), também de Joaquim Manuel de Macedo, o criado é um francês, Petit, e a professora de Leonina, a heroína da comédia, uma inglesa, Fanny. Os estrangeiros, no caso, não representam ameaça direta ao enlace amoroso posto em destaque, entre Leonina e, ainda outra vez, um jovem de nome Henrique.

No enredo imaginado por Macedo, o impedimento é resultado do aceitamento de valores e práticas reputadas como cosmopolitas, vistas portanto como impróprias no espaço da família brasileira. Conforme antecipa o nome da peça, é o apreço irrefletido pelo brilho social, de par com devaneios aristocráticos, que ameaça o casal dos heróis. Vale indicar que situação similar a esta encontra-se em $O$ demônio familiar (1857), de José de Alencar, com a diferença de que no caso da comédia de Macedo os pais da moça não possuem condições de arcar com os custos da ostentação. Esta, deste modo, é antes de mais nada tida como um investimento, cujo retorno será conseguido após o matrimônio de Leonina, no caso com um comendador endinheirado, o que garantiria o resguardo da nobreza de aparência e a salvação do pecúlio. Note-se que é esse o fundo moral em que se desenrola Caiu o ministério!, de França Júnior, onde no entanto figura ausente, ou oculto, o pólo positivo que irradia as virtudes.

Em Luxo e vaidade, Henrique, primo de Leonina, é recusado como partido, pois filho de um reles marceneiro desprezado pelo próprio irmão e pela cunhada. Mesmo Leonina mostra-se a princípio avessa ao rapaz, aceitando

7. MACEDO, 1979. Também em O defeito de família (1870), de França Júnior, surge um criado estrangeiro, o alemão Ruprecht, que embora atue como agente civilizador não introduz, no entanto, conflitos no decorrer da trama. 
sem maiores questionamentos valores e atitudes adotados pelos pais e amigos da casa. Só irá mudar de opinião graças à intervenção de um segundo irmão de seu pai, Anastácio. Fazendeiro em Minas Gerais, é este quem brande princípios considerados típicos da boa sociedade brasileira: honestidade, sinceridade, simplicidade, fraternidade, desapego, etc., que estima ameaçados ou abandonados pela impostação, por práticas impessoais e baseadas em cálculos de interesse, cuja origem identifica como essencialmente alienígena.

Através do "caipira" Anastácio, deste modo, o autor coloca em confronto o tradicional, cujo espaço de resistência é situado no interior do país, e o cosmopolita, que reinaria na corte, descaracterizando-a e distanciandoa do restante do país. Os empregados estrangeiros atuam como fiadores deste processo, sendo a eles imputada uma missão educadora, ou, invertendo o ponto de vista, corruptora. É o que fica patente, por exemplo, na cena em que Anastácio adentra na casa do irmão e dá de cara com os criados estrangeiros, que se escandalizam com sua falta de modos:

ANASTÁCIO - Oh lá!... que par de galhetas! parece uma coruja que ouve a confissão a um macaco d'Angola!...

FANNY - Ah! ficar muite vergonhade!... êste non se úse n'Ingliterre. PETIT (Levantando-se) - Que diabo de mineiro! (Indo à porta) Non entra na sala com esses botas que traz lama!...

ANASTÁCIO - Não entra na sala!

PETIT (Firme, diante de Anastácio) - On ne passe pas!

ANASTÁCIO (Ameaçando-o) - Arreda-te, malandro! quando não..

PETIT (Firme) - La garde meurt, elle ne se rend pas! (p. 30; itálicos do original).

Bastante movimentada, a trama conclui, como previsível, com a restauração da estrutura de valores e sentimentos ameaçada. Revelado o mau caratismo dos freqüentadores da família, inclusive o noivo a quem Leonina fora prometida, e estando o pai desta à beira da falência e da desonra, é o irmão desprezado que vem em socorro daqueles que o desprezaram. Quanto a Henrique, com a ajuda de Anastácio consegue salvar Leonina de um seqüestro, o que, em sintonia com a reconciliação geral e a reconversão da parte da família que se deixara viciar, assegura-lhe a posse da moça. 
Nas peças até aqui comentadas os estrangeiros são apresentados segundo um enfoque nitidamente negativo, caracterizados como velhacos, aproveitadores ou espertalhões cuja presença no Brasil deve-se acima de tudo ao pressuposto de que amealhar fortuna seria aqui fácil. Fazem uso da imagem de educados e empreendedores que os cerca, propalam formação especializada, conhecimento técnico, entretêm ótimas relações sociais, para obter de senhores e senhoras locais capital financeiro, inclusive através de casamentos. Os brasileiros, por sua vez, são considerados por eles ingênuos e ignorantes, e as ações de parte deles, embasbacados pela sedução estrangeira, confirma o diagnóstico. Outra parte dos nativos, porém, composta pelas personagens que traduzem opiniões e pontos de vista sustentados nas peças, mostra-se consciente do puro jogo de cena realizado por estrangeiros que, graças à sua intervenção, ao final acabam de maneira geral desmascarados, para o júbilo do amor próprio nacional.

Delineia-se assim um embate, que do plano das personagens se estende ao plano das idéias e dos princípios, entre uma ordem tradicional e um nova ordem que desponta, em que imperam relações de corte instrumental. A vitória da primeira sobre a segunda, que se verifica nas peças, garante ao mesmo tempo o resgate de e o elogio a valores antigos, tidos como arraigados, postos sob ameaça.

Se é verdade, como sustenta Doris Sommer, que os romances latinoamericanos do século XIX podem ser lidos, através de suas histórias de amor, como expressões alegóricas de "exigências de estados recém-estabelecidos", torna-se então legítimo delinear contornos básicos da imagem da nação brasileira que as peças em foco projetam. Em seu argumento, a autora assinala que o desejo libidinal despertado pelos textos, dificultado por obstáculos alheios ao casal, "quase sempre uma convenção social ou um impasse político", em função mesmo do seu adiamento funda e alimenta um desejo por uma outra ordem social, por uma "possível nação em que a relação se poderia consumar".

Tal ordem, nas peças, é construída a partir da preservação de princípios arcaicos, tomados como expressões efetivas do modo de ser nacional e considerados como deturpados e corrompidos pela aceitação ingênua de valores contemporâneos, internacionais ou estrangeiros, e de seus agentes. Como são estes, agentes e valores, finalmente excluídos dessa ordem, ou, no caso

8. SOMMER, 1989, respectivamente p. 1 e 13 . Ver também, da autora, Foundational fictions, 1991, onde os argumentos são expostos com base em um exercício de análise mais acurado. 
de Caiu o ministério!, predominam porém postos sob crítica e suspeição, fica claro que a nação nelas delineada caracteriza-se pela comunhão de iguais, por um sonho de pureza, por uma aversão à miscigenação, à transformação. Com toda a sua a rigidez, a solução aponta para uma inegável vontade de naturalizar a cultura. A nação ideal é situada no passado, indicada como antes já existente, em processo de dissolução por conta do progresso, pela influência e presença estrangeira julgadas nefastas.

Entre as peças do período há, todavia, algumas em que valores e seres estrangeiros são tratados segundo um prisma menos hostil. Em contraste com aquelas até agora analisadas, nestas os pares românticos centrais são formados por homens estrangeiros e moças nacionais, e as interdições são relacionadas ao plano local. Os estrangeiros, de qualquer modo, são mantidos como padrão de referência em relação ao qual os brasileiros se definem. Em Amélia Smith (1886), do Visconde de Taunay, e em Lição de Botânica (1906), de Machado de Assis, o inglês Jonh Smith e o Barão Sigismundo de Kernoberg, de origem sueca, surgem como exemplares, tendo exaltadas sua educação e conhecimentos, suas maneiras e seu caráter, enfim, os atributos resultantes de um adestramento do espírito, de um aprendizado.'

Obcecado pela ciência que tomara como razão de vida, o Barão da Lição de Botânica entra em contato com a vizinha brasileira no intuito de impedir o namoro entre a sobrinha desta e seu sobrinho, posto que avaliava que isso podia desviar a atenção do jovem pelas coisas da ciência. A princípio estimava serem racionalidade científica e jogos de amor absolutamente incompatíveis, com irremediáveis prejuízos para a primeira. Após conhecer Helena, no entanto, outra sobrinha da senhora vizinha, acaba seduzido pela sensibilidade, pelos encantos e pela vivaz perspicácia da moça. Resolve, daí, a despeito da ignorância da jovem brasileira quanto aos meandros das práticas e dos métodos científicos, tornar-se seu mestre em botânica. Não resistindo aos encantos da moça, a quem se subjuga, acaba, ao final, por pedi-la em casamento, deixando-se convencer da importância de satisfazer os apelos sentimentais.

Longe de ser ingênuo ou simplista, tal desenlace promove uma forma sutil de sanção, por parte daqueles que são distinguidos por sua ilustração, pela inteligência e racionalidade, às virtudes naturais brasileiras, resumidas na

9. TAUNAY, s/d; ASSIS, 1959. 
mulher por quem o sábio se apaixona. Esse movimento indica um desejo de fusão que, do ponto de vista nacional, é inegavelmente alvissareiro. ${ }^{10}$

Já em Amélia Smith o enfoque contempla menos os arranjos que levam ao casamento de John e Amélia que acontecimentos posteriores. As circunstâncias relacionadas ao enlace são entretanto fundamentais, já que iluminam todo o desenvolvimento da trama. Se o inglês opta por casar-se por pragmatismo, Amélia aceita ligar-se a ele por vaidade e sob pressão dos pais que, à beira da ruína e querendo preservar sua existência faustuosa, vislumbram no casamento da filha uma tábua de salvação, dada a riqueza do noivo estrangeiro. A existência honrada e serena do casal é rompida quando Amélia trai o marido, após deixar-se seduzir por um charmoso jovem brasileiro. Este vai se revelar um mero aventureiro, acabando por se afastar de Amélia que, por ele engravidada, dará à luz uma criança. John, a tudo ignorando, acredita ser dele o filho, e a existência da família prossegue sem maiores percalços até que a criança, cuja saúde era débil por herança do pai, vem a morrer. O enredo culmina com o desespero de Amélia, o que sinaliza a impossibilidade de retorno à paz conjugal.

O estrangeiro, cujas ações e atitudes se pautam pela retidão e pela força e integridade do caráter, ocupa nesta peça o pólo positivo. Os brasileiros, em contraste, pervertidos pelo apreço à riqueza e à ostentação, dominados por caprichos e vaidades, pela voluptuosidade e pela volubilidade, mostram-se indignos da confiança neles depositada. O egoísmo que os caracteriza funciona como impedimento maior para a construção de uma sociedade fundada na ética e na confiança.

Neste panorama, um lugar especial deve ser conferido a uma comédia de Martins Pena, As casadas solteiras (1845). ${ }^{11}$ Isso porque nela as relações entre estrangeiros, no caso os ingleses John e Bolingbrok, e as brasileiras, as irmãs Clarice e Virgínia, recebem um tratamento bastante original, que se pauta por sugestivas reviravoltas. A ação se desdobra em três movimentos, cada um deles correspondendo a um ato. No primeiro, o embate se dá entre os estrangeiros e o pai de suas amadas, que procura impedir a união em função do ódio que nutria pelos ingleses. As razões para tal repulsa relacionam-se à

10. Essa união não deixa de constituir uma variação do ideal de "miscigenação" com o qual, segundo Doris Sommer, o romance latinoamericano do século XIX indicava uma "via de redenção (...), uma maneira de anular a diferença e construir um sonho extensamente horizontal e fraterno de identidade nacional" (1989, p. 21). Machado de Assis, com isso, inverte a tendência xenófoba característica de outras peças do período.

11. PENA, s/d. 
política internacional, no caso as pressões inglesas para que o Brasil suspendesse o tráfico de escravos. Os estrangeiros superam o obstáculo convencendo as amadas a fugir com eles, acabando por se estabelecer na Bahia.

No ato seguinte, já casadas, as moças vêm a conhecer a verdadeira natureza dos ingleses. Estes se mostram despóticos e autoritários, prendendo-as em casa enquanto andam por teatros, bailes e hotéis, e tratando-as como senhores diante de escravas, como colonizadores diante de colonizadas. Mas elas não se resignam ao lugar que os maridos haviam lhes reservado. Alertadas por uma amiga de que o seu casamento, realizado unicamente na igreja protestante, não seria válido no caso delas, católicas, resolvem voltar a fugir, agora dos maridos, e retornam à casa do pai, no Rio de Janeiro. O terceiro ato gira em torno da tentativa de reconquista das esposas, o que os ingleses conseguem, não sem antes, porém, aceitarem se submeter a vontades e desígnios delas.

Em As casadas solteiras combinam-se portanto dois níveis de impedimentos, externos, resultantes da tensão política entre Brasil e Inglaterra, e internos, produto do descontentamento das esposas com o tratamento que lhes dedicaram os maridos. Na comédia, ao mesmo tempo, as mulheres, que constituem um dos termos que suscitam um sintomático elogio de Bolingbrok ao país, ${ }^{12}$ atuam de modo direto e decisivo para impor, aos estrangeiros exploradores, condições para aceitá-los como companheiros. Martins Pena, com isso, traz para primeiro plano um processo de negociação pelo qual o pólo local, e feminino, restringe e disciplina a atuação estrangeira.

Esta comédia de Martins Pena constitui contudo exceção. Mais ou menos conservadoras, as demais peças projetam imagens da nação segundo o diapasão da conformidade, e das mulheres como seres passivos, submissos. É inegável, mesmo assim, a importância de estrangeiros e suas representações nesse processo, quer sejam tratados como indesejáveis, quer como desejados. A despeito dos estereótipos e do enfoque caricatural a eles não raro conferido, revelam possuir importância decisiva para o esforço de discutir e de redefinir alternativas quanto ao ser ou a um mitificado voltar a ser, em suma, quanto ao destino nacional. A nação, de todo modo, objeto de interesse ou de atenção tanto destes quanto dos brasileiros, é de maneira geral reduzida a algo cuja posse e controle promete as delícias do desfrute, da felicidade daqueles que logram conquistá-la. Como as mulheres que a expressam, aliás.

12. "Brasil é bom para ganhar dinheiro e ter mulher..."; PENA, s/d, p. 270. 
Abstract: A series of plays, belonging to XIX century Brazilian theater, are characterized by the presence, among the protagonists, of characters representing foreigners. This essay analyses how these characters are put into acting in the plot of these plays. They are mainly represented or as undesirable presences, figuring as agents who challenge the status quo, or as desired by the native characters, because they could bring them civilization. Idealized images of the future projected to Brazilian nation spring from these plays.

Key words: XIX Century Brazilian theater; Representation of foreigners; Literature and nationalism.

\section{Referências Bibliográficas}

ALENCAR, José de. O demônio familiar. Rio de Janeiro: MEC/SD, 1957.

ASSIS, Machado de. Lição de Botânica e Quase ministro. In: Obras completas de Machado de Assis. São Paulo/Paraná/Rio de Janeiro/Recife: Ed. Mérito, 1959. (V. 19 - Teatro)

CAPELA, Carlos Eduardo S. Literatura e imigração: convergências. In: Anais do VIII Congresso Internacional da ABRALIC, Belo Horizonte: Abralic, 2003 (ed. em CD-Rom).

FRANÇA JÚNIOR. O tipo brasileiro e O defeito de família. In: Teatro de França Júnior Rio de Janeiro: SNT/FNA, 1980. (Tomo I)

FRANÇA JÚNIOR. Caiu o ministério! In: Teatro de França Júnior. Rio de Janeiro: SNT/ FNA, 1980. (Tomo II)

MACEDO, Joaquim Manuel. A torre em concurso e Luxo e vaidade. In: Teatro completo. Rio de Janeiro: SNT, 1979. v. 1.

PENA, Martins. Os dous ou o inglês maquinista e As casadas solteiras. In: Comédias de Martins Pena (ed. crítica por Darcy Damasceno). Rio de Janeiro: Tecnoprint, s/d.

SAYAD, Abdelmalek. A imigração (ou Os paradoxos da alteridade). São Paulo: Edusp, 1998.

SOMMER, Doris. Amor e pátria na América Latina (Uma especulação alegórica sobre sexualidade e patriotismo). Rio de Janeiro: UFRJ/CIEC (Col. Papéis Avulsos, n. 10), 1989.

SOMMER, Doris. Foundational fictions (The national romances of Latin America). Berkeley/Los Angeles/London: Un. of California Press, 1991.

TAUNAY, Visconde de. Amélia Smith. 2. ed. São Paulo, Melhoramentos, s/d. 